\title{
O POTENCIAL DE ARTE PARA UMA NOVA \\ APRENDIZAGEM: APRENDIZAGEM EXPANSIVA
}

\author{
THE POTENTIAL OF ART FOR A NEW FORM OF \\ LEARNING: EXPANSIVE LEARNING
}

\section{Bernd Fichtner}

\begin{abstract}
RESUMO
A partir da crise da educação é discutido na perspectiva da abordagem históricocultural o potencial da arte para um novo tipo de aprendizagem. A arte moderna representa uma síntese peculiar e única do conhecimento de mundo em que vivemos e, ao mesmo tempo, é um meio com o qual podemos entrar em relação conosco e com nossa subjetividade. Nessa simultaneidade se encontra um potencial para um novo tipo de aprendizagem: aprendizagem expansiva.
\end{abstract}

Palavras-chave: Crise da educação. Potencial de arte para novas formas de aprendizagem. Aprendizagem expansiva. Competência metafórica.

\begin{abstract}
Considering the crisis in education the potential of art for a new type of learning is discussed from the perspective of the historical-cultural approach. Modern art represents a peculiar and unique synthesis of the knowledge of the world in which we live and, at the same time, it is a means that allows us to enter into a relationship with ourselves and our subjectivity. In this simultaneity lies a potential for a new type of learning: expansive learning.
\end{abstract}

Keywords: Crisis of education. Potential of art to new ways of learning. Expansive learning. Metaphorical competence.

\section{A busca de um novo tipo de aprendizagem}

$\mathrm{Na}$ psicologia tradicional da aprendizagem a mais alta forma da aprendizagem representa o processo de resolver problemas ou o processo de estruturar uma determinada situação, um determinado sistema. O assim chamado problema dos nove pontos se pode descrever assim: sem levantar o lápis devem ser traçadas quatro linhas que unam esses nove pontos:

\footnotetext{
* Professor catedrático doutor da Universidade de Siegen (Alemanha), atuando no curso de Pedagogia Social e nos programas de Pós-graduação em Educação. Como orientador dos estudantes alemães, tem desenvolvido um importante trabalho de inserção dos universitários em atividades com populações periféricas, inclusive no Brasil. Tem colaborado com pesquisadores e instituições universitárias brasileiras e como conferencista e como professor visitante.
} 


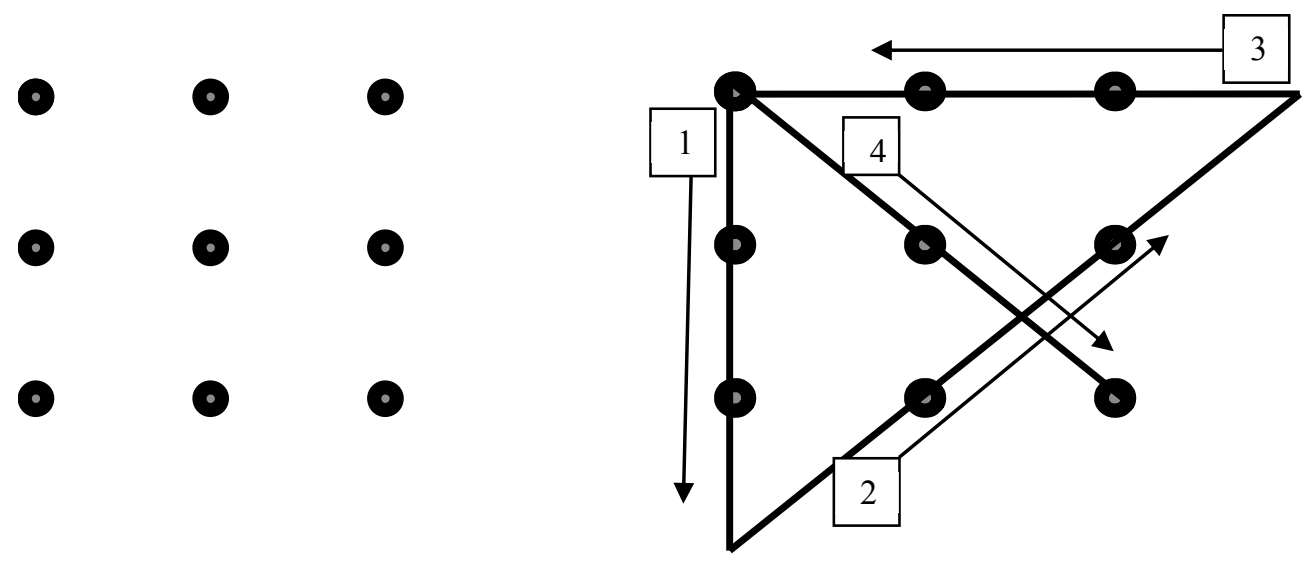

Vemos no exemplo dos nove pontos que para resolvê-lo é necessária uma ampliação do espaço do problema. O que mais se poderia esperar, do ponto de vista da solução de problemas, que propor uma nova estruturação dos modelos mentais ou dos esquemas cognitivos do indivíduo?

Mas as estruturas e resoluções dos problemas desse tipo se apresentam sempre de forma conhecida, isto é, de uma forma só reativa do aprender. O professor sempre expõe um contexto dado, um problema dado, um desafio dado. Em todos estes casos, aprender, também na sua forma mais elevada, converte-se numa capacidade de adaptação ao contexto, ao problema e ao desafio dados, desde já sabendo-se a solução a ser encontrada. O ponto central dos problemas apresentados não é a sua solução, mas a formulação de novas perguntas dos alunos, que exigem ultrapassar um problema já dado para construir um meta-nível onde as respostas podem ser formuladas, para questões que envolvem a razão de ser dos próprios problemas postos e as instâncias de suas emergências. Trata-se de perguntar não pela resposta - aliás, uma resposta já prevista - mas de formular respostas para as perguntas que explicitam contextos dos problemas levantados.

Para quem é útil que este problema seja resolvido?

Por que eu deveria tentar resolvê-lo?

Quem é que propõe este problema?

Para quem e para que serve resolvê-lo?

Atualmente assistimos, no mundo inteiro, a assim chamada crise da educação. Esta crise, em geral, é formulada através de correlações que apontam para as velocidades das mudanças sociais, rapidez impossível de ser acompanhada, em termos de uni- versalização, por modelos e métodos. Os conhecimentos se reproduzem numa progressão geométrica, e o indivíduo percebe sua impotência para dominar um saber geral, sendo obrigado, face à multiplicação de conhecimentos, a uma especialização, a uma focalização em determinadas questões em detrimento de uma visão científica mais global.

Isso torna urgente e necessária à busca de caminhos que possam incluir nas teorias de aprendizagem e de ensino as problemáticas a que as novas perguntas aludem. Caminhos que possam levar a uma maior compreensão de quem é hoje o sujeito que aprende e quem é o sujeito que ensina, de que contexto eles surgem, qual é a realidade na qual se inserem e atuam, qual é o conhecimento que precisam e como transferir esse conhecimento numa relação viva, não estereotipada. Em outras palavras, trata-se de nos interrogarmos radicalmente: por que a sociedade e os sujeitos de hoje precisam urgentemente de uma nova qualidade de aprendizagem e ensino? A capacidade de pôr em duvida a verdade, de se perguntar pelas razoes de um problema e por suas soluções, essa qualidade de não reagir apenas no contexto proposto, essa qualidade de quebrar a lógica do já estabelecido chamamos de aprendizagem expansiva ${ }^{1}$.

Vamos partir de uma hipótese polêmica: $a$ Arte Moderna representa uma síntese peculiar $e$ única do conhecimento de mundo em que vivemos

\footnotetext{
${ }^{1}$ Esse conceito se encontra sistematicamente construído num estudo de Engeström (1987). Mas a pratica de uma "aprendizagem expansiva" encontrei a primeira vez no trabalho de Carlos Maldonado com sua perspectiva visionaria, secretário de Educação em Cuiabá no período entre 2000 a 2004, fundador da Universidade Estadual de Mato Grosso (UNEMAT), secretário de estado de Educação e coordenador regional da UNESCO em Mato Grosso.
} 
e, ao mesmo tempo, é um meio com o qual podemos entrar em relação conosco mesmos e com nossa subjetividade. O que queremos defender é que nesta simultaneidade está um potencial para um novo tipo de aprendizagem.

\section{O potencial da arte para um novo tipo de aprendizagem}

Existe um campo do saber humano cujo valor é justamente a objetivação do expansivo. Um campo no qual a qualidade do expansivo está muito próxima e tem uma inesgotável riqueza: o campo da arte e das obras de arte. A arte materializa, torna visível a capacidade humana de ultrapassar limites fixados, de abandonar contextos estereotipados, de criar novos contextos. As obras de arte podem ser entendidas e analisadas como modelo desta capacidade.

Em "Psicologia da arte" de Vigotski (1998), encontramos uma idéia que nos ajuda a concretizar a tese sobre o potencial peculiar da arte. Em sua perspectiva, a obra de arte oferece, significa um meio de abstração da realidade como espaço de construção da subjetividade. $\mathrm{O}$ afeto e as emoções, neste processo, são a base elementar.

Para Vigotski a verdade de uma obra de arte nunca está no seu conteúdo, mas sim nas suas formas de representar. Uma obra de arte representa um tema, quer dizer, um "material" e ao mesmo tempo a maneira dessa representação. A forma ou o sistema das formas não são uma visualização ou ilustração de um material preestabelecido; as formas nunca se delineiam do material: ao contrário, as formas constroem um valor próprio em si mesmo. Através das formas, aparece alguma coisa que não está no material - mas só aparece quando nós relacionamos as formas com a realidade, isto é, quando nós as usamos e as aplicamos, construindo o conteúdo. As formas ou o sistema das formas orientam nossas emoções e afetos para uma realidade que a elas corresponde.

Construindo essa relação, construímos o que é o conteúdo de uma obra de arte. Diante da obra de arte, não reagimos, mas expressamo-nos como sujeitos afetivos e emocionais. A arte é o modo de ser do pensamento emocional.
Figura 1 - As meninas, Velasquez (1656).

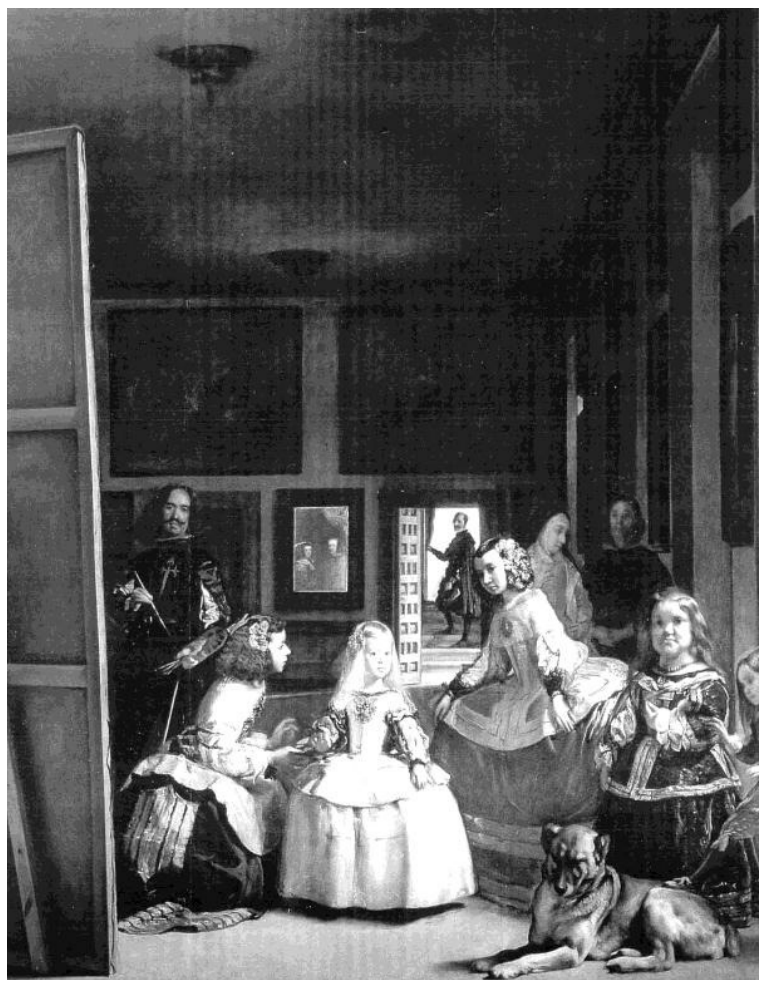

Fonte: Madri, Museu do Prado.

A genialidade do quadro 'Las meninas', de Velásquez, é apresentar uma imagem que não pode ser olhada como a representação pura e simples de uma cena, porque o modo de seu sistema de formas também obriga o observador a dialogar não com a cena em si, mas com as formas de construção de sua representação, para entender as diferentes funções que exercem na cena seus participantes e as suas formas de participação. Os inúmeros desdobramentos que o observador pode detectar, ao estabelecer diferentes sistemas de relações entre os elementos que compõem a obra, levam a diferentes compreensões segundo as relações tomadas como principais. Assim, um observador pode-se deter na reduplicação de Velásquez, o pintor, que se desdobra no nobre Velásquez, um funcionário da corte, que está na porta - retângulo branco - no fundo do quadro e cuja mão marca um conjunto outro de relações a partir das perspectivas que se podem traçar tomando a mão do nobre (ou a mão do pintor?) como ponto de partida ou de referência.

Vigotski caracteriza magnificamente esta expansão e transformação qualitativa, usando duas parábolas do Evangelho (1998, p. 307-308): 
Em realidade, come seria desolador o problema da arte na vida se ela não tivesse outro fim senão a contagiar muitas pessoas com os sentimentos de uma. Seu significado e seu papel seriam extremamente insignificantes, porque em arte acabaríamos sem ter qualquer outra saída desses limites do sentimento único, exceto a ampliação quantitativa desse sentimento. Neste caso o milagre da arte lembraria o desolador milagre do Evangelho, em que cinco ou seis pães e uma dúzia de peixes alimentam mil pessoas, todas comem até saciar a fome e os ossos restantes são recolhidos em doze cestas. Aqui o milagre é apenas quantitativo: mil pessoas que se saciaram, mas cada uma comeu apenas peixe e pão, pão e peixe. Não seria isto o mesmo que cada uma delas comia cada dia em sua casa e sem qualquer milagre?

Se um poema que trata da tristeza não tivesse nenhum outro fim senão contagiar-nos com a tristeza do autor, isto seria muito triste para a arte. O milagre da arte lembra antes outro milagre do Evangelho - a transformação da água em vinho, e a verdadeira natureza da arte sempre implica algo que transforma, que supera o sentimento comum, e aquele mesmo medo, aquela mesma dor, aquele mesma inquietação, quando suscitadas pela arte, implicam o algo a mais acima, daquilo que nelas está contido. Este algo supera esses sentimentos, elimina esses sentimentos, transforma a sua água em vinho, e assim se realiza a mais importante missão da arte. A Arte está para a vida como o vinho para a uva disse um pensador, e estava coberto de razão, ao indicar assim que a arte recolhe da vida o seu material mas produz acima desse material algo que ainda não está nas propriedades desse material. Verifica-se, deste modo, que o sentimento é inicialmente individual e através da obra da arte torna-se social ou generaliza-se.

Para Vigotski, uma obra de arte representa um meio com o qual conseguimos pensar nós mesmos e a nossa realidade numa qualidade nova. Em outras palavras, poderíamos dizer que o núcleo dessa qualidade está numa competência básica de cada homem; a sua competência metafórica, isto é, a sua capacidade de olhar algo como algo outro e novo. A arte representa, assim, a cristalização dessa competência.

Cada obra de arte é uma metáfora - um modelo concreto no qual a competência metafórica é materializada. A história da arte apresenta, neste sentido, a história da capacidade humana de ver algo como algo novo. Esta é uma capacidade fundamental e básica, num sentido antropológico, presente e viva em cada ser humano.

O enfoque de Vigotski não consiste em construir uma estética da produção nem da recepção. Não estão no centro de suas preocupações a vivência de uma obra de arte como identificação com o herói, ou como processo de expressão dos próprios sentimentos e emoções, nem os mecanismos psicológicos de produção e formação artística:

Não concluímos partindo da arte para a psicologia do autor ou dos seus leitores, pois sabemos que não se pode faze-los com base na interpretação dos signos. Tentamos estudar a psicologia pura e impessoal da arte sem relaciona-la com o autor e o leitor, pesquisando apenas a forma e o material da arte. (VIGOTSKI, 1998, p. 3).

É por isso que, para ele, a obra de arte torna-se um meio único e peculiar de uma abstração da realidade como construção de um espaço para a subjetividade e seu desenvolvimento. Os afetos e as emoções são a base de partida. Vigotski concretiza a qualidade deste meio mostrando as contradições básicas e seus mecanismos dentro de uma obra de arte.

No fundo, Hamlet representa uma figura totalmente impossível e irreal. "Se o conteúdo da tragédia, o seu matéria narra que Hamlet mata o rei, e quando mata não o faz de maneira nenhuma por vingança.” (1998, p. 237) Existe uma contradição: por um lado entre o material, o conteúdo, que trata do dever de um filho de vingar o seu pai; por outro lado a construção e formação artística, o 'sujet' (Hamlet não mata o rei). Na sua interpretação da "psicologia de arte" J. Friederich mostra precisamente como esta contradição funciona. Ela cria um espaço não-estruturado nem interpretado ou esclarecido, um espaço sem emoções, como ponto de referências para a imaginação provocando imagens, representações ideais, emoções e afetos que preenchem este espaço (FRIEDERICH, 1994, p. 60).

Através das suas contradições, a obra de arte é um meio, que não produz imediatamente emoções ou afetos, mas que cria possibilidades para que os indivíduos construam nas atividades da sua fantasia as próprias emoções ou afetos. Assim, para Vigotski (1998, p. 267) “As emoções da arte são emoções inteligentes. Em vez de se manifestarem de punhos 
cerrados e tremendo, solvem-se principalmente em imagens da fantasia."

A obra de arte é uma causa e ocasião para as reações emocionais e afetivas de um indivíduo? A resposta a esta pergunta se encontra numa ruptura revolucionária, que Vigotski realiza com a concepção tradicional da correspondência harmônica e adequada entre forma e conteúdo, substituindo o termo tradicional do conteúdo pelo termo material:

Tudo o que um artista encontra pronto, palavras, sons, fábulas correntes, imagens comuns, etc., figuras ou pessoas etc. - tudo isso constitui o material da obra de arte, incluindo-se as idéias contidas na obra. (VIGOTSKI, 1998, p. 60)

O conteúdo, devemos buscá-lo num outro lugar. Isto fica claro pela transformação do conceito da forma, quer dizer, da construção artística segundo Vigotski. A obra de arte representa algo (o material) e ao mesmo tempo a forma, o modo, a modalidade desta representação ('sujet' ou forma artística). A forma não é uma ilustração ou visualização de um material primário prefixado; a forma não se deriva deste material, mas tem o seu próprio valor.

Mediante a forma se constrói algo novo; a forma torna este algo claro e distinto do anterior, que não estava presente no material - mas isso acontece só quando nós estamos relacionando a forma com a realidade, quando nós usamos a forma, quando nós aplicamos a forma construindo um conteúdo que sempre é o nosso conteúdo.

A forma nos orienta a nós mesmos, orienta nossos afetos e às nossas emoções em direção a uma realidade que corresponde com tudo isso. Realizando esta trama, nós construímos o conteúdo como significado. Nós não reagimos em face de uma obra de arte, nós expressamos a nos mesmos como indivíduos emocionais e afetivos. A arte é, assim, um trabalho do pensar, um trabalho peculiar, um pensamento emocional e afetivo (VIGOTSKI, 1998, p. 56).

Vigotski (idem) fala da "emoção da forma" (forma-emoção) de uma obra de arte (1998, p. 44) que por sua qualidade de pensar é, sempre, uma generalização. Para o autor, generalização nunca significa algo formal ou objetivo. Generalização tem sempre uma qualidade social, resulta da relação fundamental entre "generalização e comunicação", um sistema que tem aplicação quase ilimitada para compreender os problemas do pensamento e da linguagem (VIGOTSKI ,2001, p. 12).

Vigotski apresenta, assim, uma perspectiva segundo a qual uma obra de arte é um meio particular, um meio que abre, mediante suas contradições, um espaço fictício, onde o artista e o leitor se tornam cúmplices na produção dos sentidos da obra. Através dos mecanismos da forma-emoção, esta obra universal é um meio social para um diálogo no qual o leitor pode pensar numa perspectiva nova a sua realidade e a si mesmo.

\section{A competência metafórica e a obra de arte como metáfora}

O que é uma metáfora e o que e uma competência metafórica? Geralmente a metáfora é considerada e analisada como fenômeno linguístico. No centro do interesse está a sua semântica: metáforas são palavras particulares; por isso são objetos de investigação da linguística. (LAKOFF, 1993) O nosso conceito de metáfora é mais amplo e complexo. Entendemos as metáforas, em geral, como elementos constitutivos de nossa percepção e concepção de realidade. Estruturamos, de maneira sistemática, os diferentes campos ou áreas da nossa experiência por meio de metáforas. Nelas construímos imaginações como "quadros" que criam relações entre campos, fenômenos e processos bem diferentes e contrários, formando um sistema coerente.

A competência metafórica articula-se na capacidade de ver "alguma coisa" como alguma "outra" coisa. Esta competência exige estruturar um fenômeno, uma área ou um processo, segundo o modelo de um outro fenômeno, área ou processo, numa determinada modalidade. A competência metafórica não é somente básica para a formação do sistema de referências da nossa experiência; é também fundamental para mudanças e transgressões, para a construção do novo. As fronteiras de um dado campo de experiência podem ser deslocadas, alargadas e rompidas através da construção de novas relações, destruindo, assim, referências estereotipadas e automatizadas da realidade.

Os próximos dois exemplos são extraídos da arte moderna: o "touro" e a "cabra" de Picasso. São exemplos de pensamento metafórico de um artista. 
Figura 2 - Cabeça de Touro, Pablo Picasso

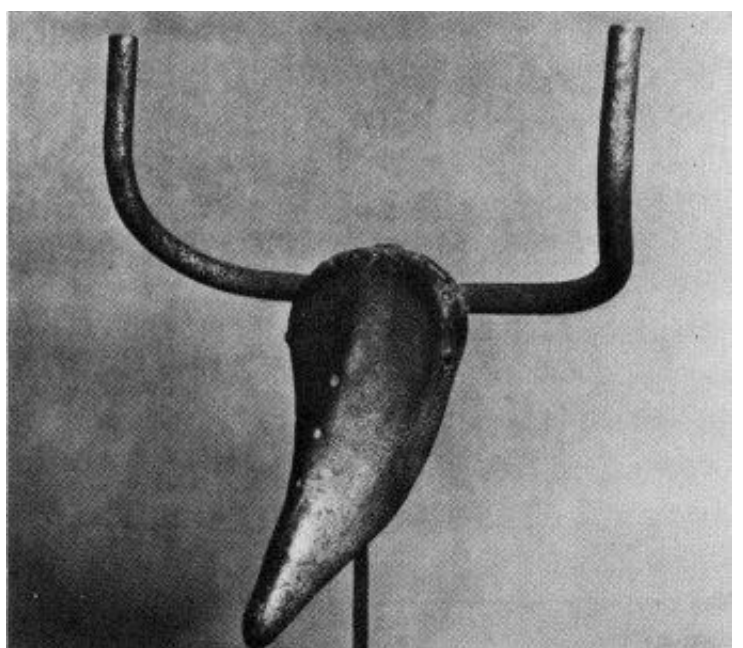

Fonte: www.arraialascores.com.br/Centroedstud/marcenaria.html.

Nesta obra o artista apresenta uma montagem de dois pedaços de uma bicicleta encontrados no lixo: um guidão e um selim. Com sua montagem presenteia-nos com a cabeça de um touro. Aqui se vê bem claro a estrutura de uma metáfora A metáfora diz: isso é isto e ao mesmo isto não é isso ${ }^{2}$. Nós, como observadores, devemos elaborar a metáfora como resposta à pergunta do por que o artista colocou duas peças de uma bicicleta desta numa maneira e não de outra forma qualquer. Qual é o resultado desse conjunto de dois pedaços que formam a cabeça de um touro? Cada um de nós pode ver aqui algo diferente: o símbolo da grandeza de Espanha, do caráter de uma mentalidade peculiar de um povo inteiro; a representação de um mito; a construção possível de representações com formas de elementos do cotidiano, desde que lidos com pensamento aberto; a informação de que as formas do mundo da cultura extraem da natureza os seus modelos; a qualidade animal dos seres humanos, com todas as conotações favoráveis deste conceito clássico, efetivamente rico, inesgotável e cheio de possibilidades e ao mesmo tempo cheio de contradições.

A qualidade peculiar da representação metafórica em uma obra de arte reside na utilização da for-

\footnotetext{
${ }^{2}$ Quando tratamos diretamente da metáfora, demonstramos a forma de funcionamento da metáfora utilizando o exemplo "A noite é uma coberta de seda azul", no qual a expressão 'coberta de seda azul' organiza uma perspectiva de olhar a noite, uma perspectiva que é ao mesmo tempo subjetiva e objetiva: a seda representa em nossa cultura riqueza, mistério, erotismo, e estes conceitos por sua vez invocam experiências, fantasias e imagens individuais.
}

ma, ou melhor, do sistema de formas, de modo bem diverso das outras maneiras de representação. Uma obra de arte apresenta o seu objeto, o seu "tema", e ao mesmo acentua a maneira desta representação em que ela o apresenta. A representação em si mesma é apresentada. Esta é uma das mais incríveis façanhas da forma da obra de arte: não alternar-se com uma superficial equiparação e correspondência de forma e conteúdo, mas antes articular, nesta façanha, uma relação sutil consigo mesma. As obras de arte são representação de algo e simultaneamente representações de si mesmas.

Retomando a "Retórica“" de Aristóteles (1926), encontramos este aspecto importante da metáfora: sua exigência da atividade e criatividade do observador. Segundo Aristóteles a metáfora é uma forma de silogismo, no qual o termo médio deve ser encontrado, desenvolvido e construído pelo ouvinte e/ou observador. Isto exige o máximo da atividade mental: Se $A$ é metaforicamente $B$, então deve existir um termo médio $T$ que pode fazer a ligação: $A$ é referente a $T$ e é nisso que $B$ é referente a $A$. (DANTO, 1984) No "touro" de Picasso este $T$ representa, claramente, com plenitude e riqueza de conotação, um mito que tem a ver com a cultura e história do povo espanhol: a montagem não representa qualquer animal, mas um animal específico. Por isso a evidência e a unicidade são aqui certamente também sintoma de um retrato cheio de efeitos retóricos e políticos.

Sobre a "cabra" de Picasso, V. C. Aldrich no seu artigo "Metáfora visual" indica que nesta e noutras obras de arte, as composições são feitas por parte de coisas que mantém sua identidade e qualidade singular e própria, mas, ao mesmo tempo, juntas criam outros significados.

A metáfora recebe uma dupla direção quando, por exemplo, em vez de gesso para formar o peito de uma cabra, coloco um cesto de vime no lugar das costelas. Então é isto um cesto de vime que se deve ver como o peito (to be seen as), e ao contrário também se pode ver, quando se olha toda a forma da cabra, suas costelas como um cesto de vime - ou seja, uma metáfora composta com dupla direção de visão. Se as costelas fossem feitas de gesso, iria o olhar somente para uma direção. Poderia ver-se somente gesso modelado como o peito de uma cabra. (ALDRICH,1983, p. 144) 
Figura 3 - A Cabra, Pablo Picasso

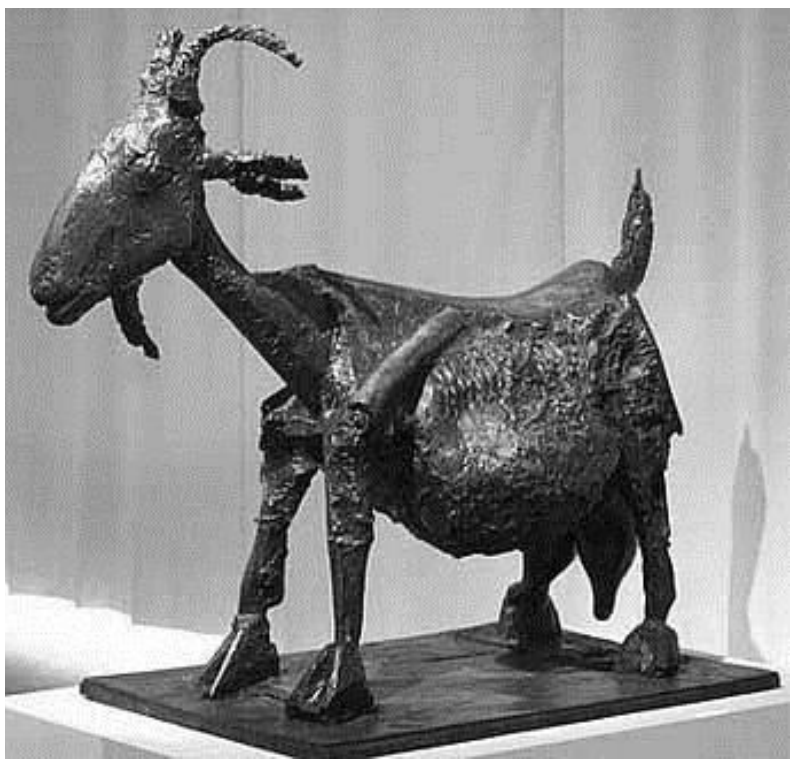

Eis o comentário de Picasso: "Eu volto o caminho da cesta para o peito: da metáfora para a realidade. Eu faço a realidade visivel, porque eu uso a metáfora" (GILOT/LAKE, 1965, p. 306). O momento icônico da metáfora é alicerce para a analogia, para a semelhança, que a metáfora usa para provocar a diferença. A tensão entre imagem e conceito torna-se produtiva no desenvolvimento do novo, de uma nova dimensão do sentido.

Uma metáfora não pode ser confundida com uma imagem acabada e estática. Ela organiza o ver como uma atividade que cria uma referência peculiar com o mundo. A metáfora não é, portanto, algo pronto, não se explica imediatamente pela sensação, vivência ou empatia. Ela exige uma atividade bem específica: compreender uma obra de arte implica em compreender a sua metáfora. O lugar da metáfora não se encontra no "tema" representado, mas na própria representação. Esta constitui o essencial para o processo de compreensão. Primeiramente cada obra de arte é forma e precisa ser compreendida como sistema de formas de representação. Cada obra de arte está situada no contexto da história das formas e, em vista deste contexto, apresenta uma resposta a questões e problemas já postos anteriormente por outras obras de arte.

Nas suas dimensões mais substanciais, o processo metafórico é um ato imaginativo. Ele realiza num nível imaginário uma semelhança que leva e preserva a diferença no nível dos significados. $\mathrm{O}$ momento icônico não perde de forma alguma sua qualidade estética e sensual, nem sua autonomia material e formal. Neste processo de comparação com o "receptor de imagem", o elemento $T$ na formulação de Aristóteles, estas qualidades são preservadas. Os exemplos de Picasso, na sua técnica genial de esculturas-colagens, nos mostram que esta dupla direção da metáfora enriquece o olhar de cada uma destas direções. Picasso entendia, sobretudo suas esculturas, como metáforas plásticas. Em vez de acabar suas obras com materiais mais tradicionais, ele usava, na maioria das vezes, sucata, como cestas velhas, vasos, peças de bicicletas, etc.

\section{Etapas de vanguarda da arte moderna}

Por caminhos extremamente dolorosos, hoje sabemos que uma sociedade que não reflete sobre si mesma, que não questiona a si mesma, poderá terminar em catástrofe ou acabar produzindo o horror ${ }^{3}$. Mas como uma sociedade inteira consegue refletir sobre si mesma? Como ela consegue construir a distância necessária para a autocrítica? De que forma ela pode colocar-se frente a frente com sua própria realidade? Para tanto, são necessários meios de distanciamento. Meios de representação são, por exemplo, as formas de uma obra de arte. Na perspectiva de Vigotski, estas formas contêm uma chave particular. E talvez nos possibilitem um compreendermo-nos a nós mesmos. Com o concurso destas formas podemos concretizar esta distância necessária e produzir para nós próprios um olhar estrangeiro com que abrimos um diálogo com o futuro, ultrapassando a mera reprodução positivista do passado.

$\mathrm{O}$ artista contemporâneo conhece as dificuldades desse compreender e desse olhar novos. Ele sempre precisa, para a sua arte, de novas relações entre sujeito e objeto, entre distância e proximidade, entre conhecimento e sentimento, entre conceitos e emoções - extremos de tal complexidade que nós só podemos entender quando nos desarmamos dos nossos valores morais, e vemo-los como possibilidades.

\footnotetext{
${ }^{3}$ Podemos ficar apenas no Século XX para recuperar na história e na nossa memória estes caminhos da dor: Primeira Guerra Mundial; Segunda Guerra Mundial; os horrores dos campos de concentração e das ditaduras que sombrearam o mapa do mundo.
} 
Apresentaremos muito rapidamente possíveis etapas da arte moderna, personificando-as nos trabalhos de Cézanne, Duchamp e Beuys. Elas elucidam a nossa proposta de que a arte representa uma síntese do conhecimento da nossa realidade e ao mesmo tempo um meio de relacionarmo-nos conosco mesmos e desenvolver a nossa própria subjetividade.

Paul Cézanne: O desenvolvimento da fotografia no século XIX representou uma revolução para as artes visuais, que ficaram liberadas da tarefa de reproduzir e transmitir as imagens da cultura presente às gerações futuras. As imagens tecnicamente reproduzíveis produzem um olhar linear, um ver que se limita a duas dimensões. Mas o olhar humano é muito mais rico e problemático, e sobretudo muito menos tranquilizante do que uma fotografia. $\mathrm{O}$ olhar humano é sempre um olhar de uma realidade complexa, não-linear. É um ver que sempre contém aproximações. Nunca deixa, se olhar livre, de perguntar, comparar, recordar, propor, substituir, retificar, etc. A visão humana não é, de maneira nenhuma, um reflexo da realidade; a visão humano nos remete ao problema da construção de uma realidade. Exatamente este é o problema principal que Paul Cézanne focaliza em suas obras.

Paul Cézanne trabalhava na inseparabilidade entre o lado objetivo e subjetivo do olhar, na inseparabilidade entre o que se vê e o que acontecerá. Este olhar nunca pode ser um ver passivo, porque é fundamentalmente construção. Como Shakespeare cria um Hamlet "impossível”, assim produz Cézanne imagens "impossíveis"; como o olhar humano, estas imagens contêm ao mesmo tempo inúmeras perspectivas subjetivas e objetivas. Isto implica muito mais que um problema formal e estético; é um problema existencial e filosófico que se relaciona diretamente com a produção cultural do saber e por isso com o desenvolvimento social e histórico da humanidade.

Quase todos os estudos sobre Paul Cézanne afirmam que ele era um gênio. Pode-se concordar com esta afirmação quando se admite que ele conseguiu quebrar e romper com todos os modelos estereotípicos canonizados de ver, modelos que se constituem e se estabelecem em todas culturas. Paul Cézanne foi possível na sua época porque ele mesmo era uma "expressão" de uma sociedade em permanente alteração. Suas propostas foram aceitas porque a sociedade precisava delas.

Baseando-se em Cézanne, as artes plásticas passam a mostrar, em todas as suas diferentes tendências, a possibilidade, de forma totalmente distinta e radical, de ser abstrato, de abstrair a realidade. É esta forma que contém, do ponto de vista segundo Vigotski, um espaço para a "generalização", para uma síntese do conhecimento da realidade e ao mesmo tempo para a reflexão sobre a própria subjetividade.

Os caminhos que Paul Cézanne trilhou se tornaram rapidamente clichês e fórmulas fixas em tendências posteriores da arte (cubismo, surrealismo, construtivismo), sobretudo quando trabalham só e exclusivamente problemas formais e técnicos. Isto porque ao formalizarem a forma, tomam a forma como material e esquecem, ao mesmo tempo, que a obra de arte opera com o material para ser um modo, uma modalidade de representação deste material.

Marcel Duchamp: Sua obra representa uma resposta à situação de crise a que se chegou pela reprodução de fórmulas e clichês. Duchamp confronta-se com uma sociedade que se encontra em uma situação particular: a sociedade industrial se solidificara, um regime de produção capitalista que, pela primeira vez, forma as estruturas de uma sociedade de consumo com seus mecanismos de "double-bind" (duplo-vinculo). Esta sociedade passou pela Primeira Guerra Mundial, e confronta-se com a Revolução de Outubro e a tentativa desta de desenvolver uma nova sociedade e um novo ser humano; sem dúvida a experiência russa traz novos sentidos aos antagônicos movimentos sociais e intelectuais com os quais a sociedade industrial e de consumo teve que se defrontar. ${ }^{4}$

Essa época de mudanças sociais nunca vistas antes na história da humanidade, força a arte a repensar minuciosamente o seu papel. Como poderia a arte tematizar tal mundo de contradições? Como construir uma arte que nos seus desdobramentos inviabilizasse sua própria reprodução em estereótipos e clichês formais?

A obra de Duchamp ironiza, quebra contextos estereotipados e fechados, ridiculariza-os, reflete e reage a problemas da sociedade capitalista e suas

\footnotetext{
${ }^{4}$ Sobre este período, ver a síntese de Hobsbawm, 1996.
} 
formas de consumo, com o seu fetiche de um conhecimento científico objetivo como base sólida de sua própria sustentação. Como os movimentos sociais antagônicos, também o fazer científico acaba mostrando que não há uma e somente uma verdade. Caos e despedaçamento das falsas seguranças, das falsas imagens e apelos, das mentiras harmonicamente bem concertadas. A indiferença de Marcel Duchamp frente aos acontecimentos sociais e políticos representa, para ele, a única forma de não ser de nenhuma maneira formalizado, esquematizado, ou reduzido a qualquer '-ismo' como futurismo, cubismo, dadaísmo etc.

Em seu neologismo, operando uma analogia, com base no termo anarquista Duchamp se nomeia-se "an-artista" (o elemento an remete também às formas de negação) e compreende seus trabalhos como uma revolta contra os mecanismos e estruturas de poder do mercado da arte, contra a sacralização e mistificação do artista e da sua obra de arte, modos de objetivá-los e torná-los mercadoria.

Marcel Duchamp volta às perguntas decisivas de Paul Cézanne e transforma-as num problema de representação compreensiva desta realidade na e através da arte, de uma representação com múltiplas possibilidades de interpretações de modo que em uma única obra ambas, representação e interpretação, possam ter um diálogo uma com a outra.

As obras de Duchamp mostram um mundo de imagens que coloca perguntas, imagens e perguntas que convém consultar. Seus múltiplos revelam as dimensões metafóricas das palavras, dos termos, dos objetos, das relações entre palavras e objetos e dos objetos entre si, e sobretudo das nossas relações com os objetos e com as palavras. A metafórica estrutura básica de sua obra não é mais submetida ao significado rigidamente hierárquico de uma cultura. Seus trabalhos tornam-se, de uma maneira intensiva, meios com que a realidade, as relações entre seus fenômenos e processos podem ser entendidos de uma nova forma. Duchamp provoca curiosidade e evoca a competência metafórica do observador, ao tematizar toda obra como metáfora, como algo tratado e visto como algo outro sobre o qual é necessário perguntar.

Joseph Beuys: Beuys, que já encontramos no episódio com que iniciamos este texto, expande dramaticamente a proposta de Marcel Duchamp em mais uma dimensão social e muito freqüentemente em mais uma atividade social. Seus trabalhos são conscientemente colocados (apresentados) no espaço público (na opinião pública) como ponto de referência social. Seus trabalhos são, para nós, sobretudo perguntas. Com que se aparenta uma sociedade que se baseia em processos sociais como processos criativos? Como se podem tematizar pessoas de uma sociedade de massas como sujeitos sociais e assim vencer os limites de gênero, raça, e classe econômica? Como podem as pessoas construir sua realidade social com sua subjetividade?

Em Beuys, a hipótese principal é que toda a pessoa é um artista. Isto significa que todos têm capacidade de compreender a arte e de se apropriar de seu saber e das formas do saber da arte de sua cultura. Em outras palavras, a arte nos faz criativos; a nossa criação faz a arte. Somente assim as obras se tornam "alimentos" que possibilitam a qualquer pessoa fazer habitável o mundo, desenvolver o mundo em que vive, entender a realidade e projetar e ter um futuro.

\section{Uma nova aprendizagem, a metáfora e a obra de arte}

Os exemplos aqui apresentados, tanto aqueles que envolvem o desenvolvimento da capacidade metafórica, que sempre exige a saída do quadro preexistente para enxergar de fora o que se vê quanto aqueles que materializam e imortalizam esta capacidade metafórica, as obras de arte, mostram-nos que os processos de compreensão são enriquecidos pela atividade criativa que exige tomar $A$ como sendo $B$, e ao mesmo tempo $B$ como não sendo $A$. Ao obrigar a este raciocínio, a metáfora se apresenta como um sistema de formas que exige duplo trânsito: pelos seus próprios temas e pela representação que ela própria é em seu sistema de formas. Na obra de arte, este processo nos apresenta uma síntese do conhecimento sobre a nossa realidade e ao mesmo tempo um espelho, com o qual vemos nós mesmos, já que o raciocínio exige que formulemos o não formulado: o elemento aristotélico $T$ no qual se encontra o terreno de sustentação da metáfora, que a própria obra de arte também é.

Neste sentido, podemos concluir que as obras de arte apresentam uma materialização do proces- 
so de uma aprendizagem expansiva, aquela que nos exigiu sairmos do quadro proposto para com quatro traços unirmos nove pontos sem levantar a mão. As obras de arte nos esclarecem que esse processo é, na sua essência, um processo complementar.

- tanto interno quanto externo

- tanto objetivo quanto subjetivo

- tanto individual quanto social.

Karl Marx (2001) analisou, com base em sua concepção do fetichismo da mercadoria, as possibilidades universais de nossa sociedade de transformar as relações humanas em mercadorias, inclusive nosso tempo de vida e a nossa própria vida. Ao dinheiro cabe a função de totem secularizado da época moderna. Bateson (1991) analisa, com a sua concepção de "duplo vínculo", as contradições dessa sociedade e seus efeitos para os indivíduos. As mensagens da educação e da reprodução desta sociedade estão sempre a apontar para o valor capitalista - ser sujeito nesta sociedade é ser produtor e consumidor de mercadorias - e ao mesmo tempo apontam para valores transcendentais - ser sujeito nesta sociedade é ser altruísta, cidadão generoso e participativo.

Pensar as contradições do nosso cotidiano na perspectiva da arte poderia ser uma chave para conscientemente rever nossas relações. Esta perspectiva poderia ser sintetizada no seguinte princípio: liberar o pensamento que foi dominado durante séculos por fórmulas, clichês e estereótipos.

A arte moderna não é didática, não é pedagógica, não é técnica. Ela é um pensar - um pensar sobre isso tudo, inclusive o que ainda não foi explicitado. A arte busca também o que está por trás do até agora dito, para reencontrar o dizer. A arte moderna mostra algo que à primeira vista não é compreensível. E ela se torna totalmente incompreensível se nós, para entendê-la, usamos somente os outros e não a nós mesmos. Isto não quer dizer que a arte implica um individualismo sem fronteiras, ou um subjetivismo objetivado sem relações com a alteridade. O que importa é que o olhar, o pensar a arte moderna exige de cada um o retorno a si mesmo depois da contemplação estética. O novo compreender contém esta mudança qualitativa. O novo compreender implica compreender o futuro como uma projeção do presente e do passado em um tempo que ainda não foi vivido.
Nós supomos que a estética do cotidiano seja o nível decisivo de mediação, sobre o qual podem se formar perspectivas e modelos de um novo tipo de aprendizagem. Mas é também no nível da estética do cotidiano que simultaneamente se geram os bloqueios e impossibilidades de construção do novo porque naturaliza as relações e nele há que haver a presença do outro para ajudar a produzir o distanciamento capaz de fazer ver o novo no que se vê a todo o momento.

Este nível de uma estética do cotidiano dos alunos pode-se ser descrito dividindo-o em partes tão óbvias que podem surpreender: o caminho diário para a escola; os caminhos do seu lazer e suas outras ocupações; os diferentes "espaços de vida" com seus diferentes objetos; os diferentes orçamentos temporários com que organizamos nossas vidas. Em todos estes diferentes momentos, há para observar traçados e arquiteturas, roupas e modas, cortes de cabelo e enfeites etc. E, nesses cotidianos, há tipos de música que os jovens ouvem e as que não ouvem e suas razões para ouvir ou não ouvir, os programas de televisão que vêem, os livros que lêem e as revistas que folheiam. Há os rituais das amizades e das relações eróticas. Há as relações com os pais e outros familiares. Há os contatos com colegas. Enfim, há a totalidade das múltiplas condições e relações de vida.

Essa visão geral deve ser concretizada para nelas descobrir suas profundas contradições. $\mathrm{Na}$ estética do cotidiano os adolescentes realizam suas relações com si mesmo e com o mundo; ao mesmo tempo a estética do cotidiano é o fator central de uma homogeneização e de uma globalização da sociedade de consumo, em que se expressam todas as contradições das nossas sociedades.

Envolver-se com esta realidade da estética do cotidiano implica atenção para o que se expressa e que não mais escutamos. Trazer o cotidiano para dentro da escola, para dentro da sala de aula é trazer a flexibilidade para os planejamentos, é deslocar o processo de ensino de um compromisso com o passado para assumir um compromisso com o futuro. Isto não se faz sem muitas dificuldades, até porque não temos a experiência histórica de uma escola com compromissos com o futuro. Normalmente nós professores não conseguimos sequer nos aproximarmos da cultura dos jovens, muito menos entendê-la. 
No entanto, as dificuldades de construir tal ensino não justificam a negação de sua possibilidade. Se negamos esta estética do cotidiano, que existe tão presente em nossa realidade, como poderemos entrar em um diálogo com as experiências dos jovens e construir pontes entre uma cultura do passado, seus saberes acumulados e o futuro?

Como mostram as perspectivas de Vigotski, uma obra de arte não é um apelo visual aos sentidos que nos força a reviver emoções e sentimentos de um autor - não seria nada mais do que aquele milagre "melancólico" da multiplicação de pão e peixe, ou seja, o prato de todo o dia. Uma obra de arte não nos diz nada se não se trabalha com o conhecimento nela cristalizado, se não é usada simultaneamente como um meio para saber algo mais sobre nós mesmos.

Para concretizar estas perspectivas e associá-las à estética do cotidiano, vivida pelos jovens com os quais trabalhamos, tentamos construir as pontes entre arte e estética do cotidiano juntando com os adolescentes as metáforas linguísticas vivas com as quais eles estruturam e organizam suas experiências. Eles traduzem então estas metáforas em todas as formas de representações possíveis: imagem visual, ações dramáticas, formas musicais. Tornar-se consciente da própria competência metafórica significa apropriar-se da capacidade "de ver algo como algo". Cremos que este é um caminho para desmistificar a arte moderna, supondo que toda a obra de arte tem a estrutura básica de uma metáfora e nela é incorporada, de uma maneira muito excepcional, a competência metafórica. Metáforas e obras de arte não mudam o mundo, mas o fazem mutável.

Assumindo essa concepção de arte, investindo no tipo de raciocínio a que ela obriga, pela criação de um território externo aos quadros fornecidos para solucionar problemas, e por isso mesmo não repetindo as soluções já dadas, estaremos sempre literalmente numa "zona de desenvolvimento iminente", ou seja, estaremos sempre na construção de um novo. É a este modo de compreender o aprender, denominamos de "aprendizagem expansiva".

Expressamos nossa profunda convicção de que as artes trazem dentro de si um potencial enorme para a construção de um sujeito capaz de reconhecer na criação artística uma síntese de sua realidade e uma transgressão ao estabelecido como forma de recriá-lo e recriar-se.

\section{Referências}

ARISTOTLE. Art of Rhetoric. Havard: Havard University Press, 1926.

ALDRICH, V. (1983). Visual Metaphor. In: Journal of Aesthetic Education. no.2, 73-86, 1983.

BATESON, G. Passos hacia una Ecologia de la Mente (Steps to an ecology of mind 1972). Buenos Aires: PlanetaCarlos Lohlé, 1991.

DANTO, A. C. Die Verklärung des Gewöhnlichen. Frankfurt: Suhrkamp, 1984.

ENGESTRÖM, Y. (1987). Learning by Expanding. Helsinki: Orienta-Konsultit Oy, 1987.

FRIEDERICH, J. Sprache und Affekt. Vygotskij und Volosinov als Theoretiker der Sprachformen. In: Der Deutschunterricht. Jg. 46 , H. 4, 56 - 81, 1994.

GILOT, F. / LAKE, C. Leben mit Picasso. München: Diogenes, 1965.

HOBSBAWM, E. Era dos extremos. O breve século XX 1914-1991. São Paulo: Companhia das Letras. 1996.

LAKOFF, G. The contemporary theory of metaphor. En: ORTONY, A. (ed.), Metaphor and Thought (2nd ed.), Cambridge: Cambridge University, 1993.

MARX, K. (2001). Elementos fundamentales para la Crítica de la Economía politíca (Grundrisse) 1857-1858. Buenos Aires: siglo XXI editores argentina, 2001.

PRESTES, Z. Quando não é quase a mesma coisa. Traduções de Lev Semionovitsch Vigotski no Brasil. Campinas: Autores Associados, 2012.

VIGOTSKI, L. S. Psicologia da arte. São Paulo: Martins Fontes, 1998.

VIGOTSKI, L. S. A construção do pensamento e da linguagem. São Paulo: Martins Fontes, 2001.

Data de submissão: março de 2013

Data de aprovação: maio de 2013

\footnotetext{
${ }^{5}$ Invés de "zona de desenvolvimento proximal" usamos a tradução correta de Z. Prestes: "zona de desenvolvimento eminente" (2012, p. 190-207).
} 
